\section{DIAGNÓSTICO SOBRE A ABORDAGEM DAS PRÁTICAS CORPORAIS DE AVENTURA EM AULAS DE EDUCAÇÃO FÍSICA ESCOLAR EM ILHÉUS/BA}

\author{
AN ASSESSMENT OF THE APPROACH TO ADVENTURE BODILY PRACTICES \\ IN SCHOOL PHYSICAL EDUCATION IN ILHÉUS, BA
}

\author{
DIAGNÓSTICO SOBRE EL ENFOQUE DE LAS PRÁCTICAS CORPORALES DE \\ AVENTURA EN CLASES DE EDUCACIÓN FÍSICA ESCOLAR EN ILHÉUS / BA
}

\author{
Alexander Klein Tahara*, Suraya Cristina Darido**
}

Palavras chave:

Educação Física.

Natureza.

Professores

escolares.
Resumo: Esta pesquisa qualitativa teve como objetivo realizar um diagnóstico junto aos professores de Educação Física da rede municipal e estadual de ensino de Ilhéus/BA, a respeito da abordagem do conteúdo referente às Práticas Corporais de Aventura (PCA), avaliando suas opiniões sobre questões que tangenciam o processo de inserção nas aulas. Como instrumento para coleta dos dados foi utilizada uma entrevista semiestruturada contendo quatro questões, aplicada para 18 professores (dez homens e oito mulheres), faixa etária de 25 a 57 anos, todos com formação acadêmica em Educação Física. Os dados foram analisados utilizando-se a Análise de Conteúdo, e os resultados indicam que a maioria dos professores desconhece as PCA, sendo que somente quatro professores já inseriram tal conteúdo em suas aulas. Entretanto, a maioria dos professores aponta que existe a viabilidade em pensar estratégias para que haja inserção dessas práticas em suas aulas.

Keywords:

Physical Education. Nature. School teachers.

Palabras clave: Educación Física. Naturaleza. Maestros.
Abstract: This qualitative research assessed Physical Education teachers of municipal and state schools of llhéus, Bahia, regarding their approach to Adventure Body Practices (ABP), by evaluating their opinions on issues related to the inclusion of that content in class. A semi-structured interview containing four questions was used to collect data. It was applied to 18 teachers (ten men and eight women) aged 25-57, all of them with academic training in Physical Education. The data were examined by Content Analysis and the results indicated that most teachers were not aware of $A B P$ and only four had already included such content in their classes. However, most teachers pointed out that strategies for including these practices in their classes are viable.

Resumen: Esta investigación cualitativa tuvo como objetivo realizar un diagnóstico junto a los profesores de Educación Física de la red municipal y estatal de enseñanza de llhéus/ BA, acerca de la forma de abordar el contenido referente a las Prácticas Corporales de Aventura (PCA), evaluando sus opiniones sobre cuestiones referentes al proceso de inserción en las clases. Como instrumento para la recolección de datos se utilizó una entrevista semiestructurada que contenía cuatro preguntas, aplicada a 18 profesores (diez hombres y ocho mujeres), con edades de 25 a 57 años, todos con formación académica en Educación Física. Los datos fueron analizados utilizando el Análisis de Contenido, y los resultados indican que la mayoría de los profesores desconocen las PCA, y que solamente cuatro profesores ya introdujeron tal contenido en sus clases. Sin embargo, la mayoría de los profesores señalan que es viable pensar estrategias para que se incorporen estas prácticas en sus clases.
*Universidade Estadual de Santa Cruz. Ilhéus, BA, Brasil.

E-mail: alexipatinga@yahoo.com

**Universidade Estadual Paulista. Rio Claro, SP, Brasil.

E-mail: surayacd@rc.unesp.br

Recebido em: 27-07-2017 Aprovado em: 19-09-2018

DOI https://doi.org/10.22456/1982-8918.75302 (c) (1) (8) Licence 


\section{INTRODUÇÃO}

A predominância dos esportes enquanto conteúdo hegemônico nas aulas de Educação Física na escola é um assunto que vem sendo discutido há considerável tempo, como em Soares et al. (1992), Kunz (2004), Bracht (2005), Rodrigues e Darido (2008), Frizzo (2013), entre outros estudos. As modalidades esportivas tradicionais (futebol/futsal, basquete, vôlei e handebol) são presença quase certa nas quadras e demais espaços destinados às aulas.

Diante das possibilidades que a Cultura Corporal de Movimento apresenta, tais como ginásticas, lutas, dança, capoeira, atletismo, entre outros, imagina-se que, em se tratando de aulas de Educação Física Escolar, torna-se necessário contribuir para que haja uma diversificação nos conteúdos trabalhados pelos professores e estímulo aos alunos para a vivência de novas experiências e aprendizagens.

Sobre o cotidiano das aulas de Educação Física, Franco, Cavasini e Darido (2014) evidenciam a importância de se promover a inclusão de novos conteúdos na escola. Para isso, torna-se necessário superar determinadas barreiras construídas ao longo do tempo, como a tradição das práticas esportivas, a qual é, sem dúvida alguma, uma das mais expressivas.

Especialmente ao longo da última década, alguns autores propuseram-se a refletir sobre a inserção das Práticas Corporais de Aventura ${ }^{1}$ (PCA) enquanto um conteúdo a ser tratado e discutido pela Educação Física nas escolas, como Betrán e Betrán (2006), Dejager (2006), Pereira e Armbrust (2010), Franco et al. (2011), Fernández-Rio e Suarez (2014), Maldonado e Silva (2015), Tomio et al. (2016), Tahara e Darido (2016), entre outras pesquisas que discutem o tema.

Vale ressaltar que a Base Nacional Comum Curricular (BRASIL, 2017), documento oficial do Ministério da Educação, entende as PCA como um conteúdo a ser desenvolvido pela Educação Física Escolar no ensino fundamental, nos $6^{\circ}$ e $7^{\circ}$ anos com as práticas urbanas e nos $8^{\circ}$ e $9^{\circ}$ anos com as práticas na natureza. Nesse documento, o conceito de aventura está interligado à exploração de formas de experimentação corporal centradas nas perícias e proezas provocadas pelas situações de imprevisibilidade, que se apresentam quando 0 praticante interage com um ambiente desafiador, seja na natureza ou em meio urbano, sendo capaz de gerar a vertigem e o risco controlado (BRASIL, 2017).

Nesse sentido, Schwartz (2018) comenta que as atividades centradas na aventura se diferenciam de outras formas de vivências por conterem características peculiares, como a percepção de risco controlado, além de possuírem inúmeros atrativos, podendo ser desenvolvidas tanto em ambientes naturais (em contato direto com a natureza, envolvendo a terra, a água e o ar), como em ambientes artificiais e urbanos (rampas de skate nas cidades, paredes de escalada em academias, etc.).

Desta forma, pensando na diversidade de práticas que remetem à aventura na natureza, podemos citar alguns exemplos: aquáticas (rafting, surfe, kitesurf, mergulho livre e autônomo, boia cross, stand up paddle, canoagem, wakeboard, etc.), terrestres (trekking, mountain bike, corrida de orientação, veículos off-road, snowboard, sandboard, etc.), aéreas (paraquedismo, base jump, voo livre, parapente, arvorismo e tirolesa, etc.). Além das práticas

10 motivo pela escolha do termo "Práticas Corporais de Aventura" deve-se ao fato da Base Nacional (BNCC/BRASIL, 2017) adotar tal terminologia em seu documento, sendo que as PCA podem ocorrer tanto no meio urbano como na natureza. Na literatura específica se encontram frequentemente os termos AFAN (Atividades Físicas de Aventura na Natureza), Esportes de Aventura, Atividades de Aventura, Esportes Radicais, entre outros, e por isso no decorrer deste trabalho será mantido o termo original utilizado por cada autor citado. 
urbanas e realizadas nas cidades, seja em praças e parques públicos, seja em academias e/ou espaços fechados (skate, parkour, patins, bike, slackline, parede de escalada artificial).

Cabem aqui algumas inquietações: será mesmo que as PCA são difundidas (como deveriam) em aulas de Educação Física nas escolas? Será que este é um conteúdo que apresenta facilidade para ser inserido junto aos alunos? Ou haveria dificuldades para que determinadas práticas pudessem ser abordadas pelos professores em aulas?

Assim, nesta pesquisa buscou-se realizar um diagnóstico junto aos professores de Educação Física da rede municipal e estadual de ensino de llhéus/BA, a respeito da abordagem do conteúdo referente às PCA, avaliando suas opiniões sobre questões que tangenciam o processo de inserção nas aulas de Educação Física Escolar.

\section{MATERIAL E MÉTODO}

\subsection{Natureza da pesquisa}

Esta pesquisa teve um caráter qualitativo, sendo uma pesquisa do tipo exploratória. Thomas, Nelson e Silverman (2007) evidenciam que a abordagem qualitativa tem uma importância significativa por envolver a observação e obtenção de dados em um ambiente, sendo registrado e detalhado o que acontece neste local. Envolve um processo de interação científica com os participantes, sendo que a sensibilidade e a percepção do pesquisador são essenciais na busca e no processamento de observações e respostas das questões acerca do estudo.

Richardson (1999) também credita importância à pesquisa qualitativa, a qual tem por finalidade investigar situações complexas e particulares de determinado contexto. Deste modo, procura analisar a interação das mais diversas variáveis, colaborando na transformação de um grupo específico ou mesmo no intuito de compreender as peculiaridades do comportamento dos participantes.

\subsection{Participantes}

Os participantes do estudo foram 18 professores (dez homens e oito mulheres) que ministram aulas de Educação Física Escolar, pertencentes à rede municipal e estadual de ensino da cidade de llhéus.

A faixa etária variou de 25 a 57 anos, todos com formação acadêmica em Educação Física, sendo que o tempo decorrido de conclusão da graduação variou de três a 25 anos.

Do total de participantes, dez têm pós-graduação em nível de especialização e outros oito somente o nível de graduação. Não houve a ocorrência de nenhum participante com nível de mestrado e/ou doutorado. Em relação à atuação na Educação Física Escolar no ensino fundamental, o tempo variou de um a 18 anos.

A seleção desta população foi do tipo proposital, como enfocam Thomas, Nelson e Silverman (2007), pelo fato de que nas pesquisas com ênfase na abordagem qualitativa a seleção dos participantes se dá pelo fato deles possuírem determinadas características e/ou particularidades que se relacionam com o objeto de pesquisa investigado. 
No caso deste estudo, os critérios de seleção foram professores de Educação Física da rede pública de ensino de llhéus que ministram aulas em âmbito escolar para o ensino fundamental $6^{\circ}$ e $7^{\circ}$ anos. Fatores como gênero, idade ou tempo de atuação na docência não foram determinantes para a inclusão como professores participantes do estudo.

\subsection{Procedimentos}

Esta pesquisa teve seu protocolo aprovado pelo Comitê de Ética em Pesquisa com Seres Humanos (CEP), do Instituto de Biociências de Rio Claro da Universidade Estadual Paulista, sob número do parecer 2.021.650.

Para dar início à pesquisa exploratória, o pesquisador entrou em contato com a Diretoria Regional de Educação - DIREC 6 e também com a Secretaria Municipal de Educação de llhéus, no propósito de conseguir consentimento para ir às escolas da referida cidade. Na cidade de Ilhéus o número total de escolas públicas que têm o ensino fundamental nos ciclos finais é de 28 instituições, localizadas do norte, ao centro e sul da cidade, inclusive bairros distritais.

Para dar início ao Processo de Consentimento Livre e Esclarecido, o pesquisador visitou as escolas e investigou se haveria anuência da direção e coordenação pedagógica destas instituições em permitir a realização do estudo e, em caso positivo, verificou quais professores de Educação Física destas escolas estavam dispostos a serem participantes.

A partir dessa sondagem, os professores foram esclarecidos acerca da pesquisa e convidados a participar, recebendo todas as informações necessárias. No caso de sucesso nessa abordagem, os participantes receberam o Termo de Consentimento Livre e Esclarecido (TCLE) para que fosse lido e compreendido, antes da concessão do seu consentimento livre e esclarecido. Eles foram devidamente instruídos para o preenchimento correto, prevendo-se a possibilidade de interrupção da participação a qualquer momento sem qualquer tipo de prejuízo ou danos.

Foi então realizada uma entrevista semiestruturada junto a esses professores, no intuito de se fazer um diagnóstico para compreender como se dá a abordagem do conteúdo das PCA no desenvolvimento das aulas em contexto escolar.

\subsection{Instrumento}

Como instrumento para a coleta dos dados junto aos professores, foi utilizada uma entrevista semiestruturada contendo quatro questões:

1) $O$ que você acha da inserção do conteúdo das Práticas Corporais de Aventura (PCA) em aulas de Educação Física Escolar? Por qual(is) motivo(s)? Justifique.

2) Em suas aulas, você já fez (ou faz) uso do conteúdo das PCA? Quais práticas você já utilizou? Tem alguma prática que você gostaria de fazer uso e não consegue? Por qual motivo?

3) Quais dificuldades/obstáculos, caso existam, impedem a inserção do conteúdo das PCA em suas aulas? Justifique.

4) Você enxerga a possibilidade de inserção das PCA em suas aulas de Educação Física? De que forma? 
A entrevista semiestruturada é um tipo de instrumento que dá liberdade para direcionar as perguntas ao entrevistado, com o propósito de desenvolver uma situação direcionada e adequada à realização da entrevista, e assim o entrevistador pode explorar ainda mais uma determinada questão, que geralmente é aberta e pode ser respondida dentro de uma conversa aparentemente mais informal (MARCONI; LAKATOS, 2002).

\subsection{Análise dos dados}

Os dados coletados nesta pesquisa foram analisados descritivamente, por meio da técnica de Análise de Conteúdo, a qual tem a vantagem de favorecer a visualização dos conceitos mais significativos ao estudo presentes nos depoimentos dos participantes. Tal tipo de análise favorece o foco apenas nas questões mais relevantes para a pesquisa, representando desta forma uma ótima maneira para descrição, análise, compreensão e classificação de qualquer tipo de processo vivenciado, procurando retratar as questões meramente qualitativas e que sirvam para realização de uma análise adequada (RICHARDSON, 1999).

Para que haja sucesso nesse tipo de técnica torna-se importante a realização de uma classificação, em etapa prévia, possibilitando visualização e comparação dos resultados, bem como a elaboração e o estabelecimento de categorias para tornar mais fácil a análise do material coletado (MARCONI; LAKATOS, 2002).

Bardin (2004) explicita que essa técnica é caracterizada como um procedimento de fragmentação de textos, permitindo evidenciar apenas o que é significativo das respostas, facilitando assim a compreensão dos resultados e a categorização dos conteúdos, os quais nortearão 0 agrupamento das respostas em categorias temáticas semelhantes.

\section{RESULTADOS E DISCUSSÃO}

Ressalta-se que esta seção do texto será dividida em três categorias principais a partir da análise temática: conhecimento sobre as PCA; possibilidades acerca da implementação das PCA nas aulas escolares e, por fim, dificuldades que impedem a efetivação da proposta.

\subsection{Conhecimento sobre as PCA}

Em relação às PCA, sete participantes comentaram ter conhecimento sobre as PCA, ao passo que três disseram conhecer um pouco tais práticas e outros oito mencionaram não possuir nenhum tipo de conhecimento a respeito.

O depoimento de dois indivíduos evidencia esta questão acerca do contraste em conhecer (ou não) as PCA:

P2: [...] e eu conheço até bem estas práticas porque tive na minha graduação uma disciplina sobre isso, duas, na verdade, e eu também já fui mais, mas ainda sou um praticante de algumas modalidades, como, por exemplo, o surfe e a bike nas trilhas, faço sempre que dá [...].

P8: Realmente não conheço nada a respeito destas práticas de aventura, o que sei é que são meio perigosas, com muito risco [...] e eu nunca fiz nada disso, nunca pratiquei nada [...] vi algumas vezes em reportagens e na TV, mas não conheço nada não [...]. 
A esse respeito, Freitas et al. (2016), ao avaliarem a implementação de um programa de PCA para o $7^{\circ}$ ano do ensino fundamental, constataram que o professor de Educação Física jamais havia pensado ou mesmo trabalhado com algum tipo de PCA anteriormente durante as aulas. Para o professor, este conteúdo foi pouco abordado durante sua formação na graduação e ele praticamente não tinha conhecimento algum para ministrar este tipo de aula para seus alunos.

A respeito desta questão referente à formação inicial, Inácio et al. (2016) discorrem sobre indicações da presença das PCA em universidades brasileiras, seja como disciplina própria ou como conteúdo de outras, e constatam uma carência nesse sentido, enfocando que "[...] é preciso sanar primeiro a lacuna da graduação para que o conteúdo passe a ser efetivamente ensinado na educação básica" (INÁCIO et al., 2016, p.180).

Reconhece-se que a presença das PCA nos currículos dos cursos de formação inicial em Educação Física ainda se configure como uma importante lacuna a ser preenchida, uma vez que muitas instituições de ensino superior ainda não abordam o tema de maneira específica na formação inicial.

Nesse sentido, Severino, Pereira e Santos (2016) evidenciam que formação em aventura é ainda incipiente nos cursos de Educação Física, e diante de tal fato, é necessário que os professores devam buscar conhecimentos além daqueles obtidos na graduação. Cabe à universidade abrir mais espaço para disciplinas que abordem o tema, não deixando o futuro professor fora desta discussão, tematizando a aventura para se ampliar os conhecimentos na área.

Esta questão referente à formação inicial e o desconhecimento dos próprios professores de Educação Física em relação a uma possível inserção das PCA em aulas parecem mesmo se tornar um dos principais fatores que tendem a inviabilizar e dificultar o processo em conseguir oportunizar aos alunos a vivência e o aprendizado do conteúdo relacionado à aventura.

Capaverde, Medeiros e Alves (2012) salientam que o desconhecimento dos próprios professores em relação a uma possivvel inserção dessas práticas no contexto educacional torna-se um dos principais fatores que inviabilizam e dificultam muito o processo em conseguir oportunizar aos alunos a vivência e o aprendizado do conteúdo relacionado à aventura.

Ao tomar como referência a pluralidade cultural que permeia a escola e as aulas de Educação Física, o professor em sua prática pedagógica deve proporcionar aos alunos a possibilidade de acessar e ter conhecimento em relação ao maior número possível de manifestações que compõem a Cultura Corporal de Movimento e, neste caso, incluir também as práticas corporais que remetem à aventura (BOCCHINI; MALDONADO, 2014).

Pensa-se que é possível (e necessário) contextualizar e tratar as PCA como parte da Cultura Corporal de Movimento pelo fato de que tais práticas são manifestações corporais que fazem parte da história da humanidade. Afinal, é possível assistirmos em filmes ou mesmo analisando imagens em revistas e livros que desde os primórdios os indivíduos iam ao encontro da natureza para sua subsistência básica, seja escalando montanhas para procura de alimentos e abrigo, descendo corredeiras em embarcações feitas por tronco de árvores, mergulhando em rios para pesca e banho, entre tantas outras possibilidades que às vezes nem é possível imaginar como pudesse ocorrer na época. 
Diante disso, pelo fato de que todas as manifestações de PCA envolverem o movimento como uma orientação/ação básica, além do fato de tais práticas fazerem parte da cultura de diferentes povos, é que se imagina que há a importância de se resgatar estas práticas e leválas para a escola como um conteúdo a ser tratado e problematizado pela área da Educação Física.

\subsection{Possibilidades acerca da implementação das PCA na escola}

As aulas de Educação Física Escolar, em geral, são centradas em propostas de práticas esportivas visando mais ao treinamento esportivo e às competições estudantis nas modalidades tradicionais. Os conteúdos da Educação Física devem ser revistos e aplicados em atividades e vivências variadas, oferecendo um conhecimento que irá além do desenvolvimento de habilidades motoras em esportes coletivos. Neste caso, as práticas que remetem à aventura podem promover aos alunos a possibilidade de experimentação do risco controlado, a novidade e ineditismo, a sensação de vertigem, o desafio de superar-se em práticas não tão habituais em aulas escolares, entre outros aspectos. Diante disso, entende-se como necessária a inclusão destas PCA como conteúdo das aulas de Educação Física nas escolas.

Há cerca de duas ou três décadas, pensar na inserção das PCA em aulas de Educação Física Escolar poderia soar um tanto quanto utópico. Entretanto, nos dias atuais, pensar nesta mesma inserção pode ser um tanto quanto exequível e real, como demonstram Dejager (2006), Franco et al. (2011), Bocchini e Maldonado (2014), Maldonado e Silva (2015), Freitas et al., (2016), Sutherland e Legge (2016), entre outros estudos.

Sobre a importância da inserção das PCA, Maldonado e Silva (2015) entendem que essa experiência pedagógica pode acarretar aos alunos a vivência, compreensão, reflexão e produção de conhecimento sobre essa manifestação da Cultura Corporal de Movimento. Dentro das três dimensões do conteúdo (conceitual, procedimental e atitudinal), os autores comentam que é possível estudar a história e as características dos diferentes esportes radicais, refletir sobre os discursos presentes na mídia sobre estas práticas e experimentar uma variedade de modalidades na escola durante as aulas.

Sutherland e Legge (2016) salientam que, nos dias atuais, as recomendações educacionais incluem a relevância pedagógica do conteúdo e a importância da compreensão/ experimentação da educação pelas práticas de aventura, sendo necessário o emprego de abordagens metodológicas inovadoras para explorar mais esta temática em aulas perante os alunos.

No caso desta pesquisa, em relação às possibilidades acerca da implementação das PCA na escola, dez professores apontaram que existe a viabilidade em se pensar estratégias para que haja inserção das práticas em suas aulas, enquanto para o restante dos docentes tais possibilidades são mínimas quando comparadas às dificuldades que permeiam este processo.

Somente quatro participantes relataram já ter tratado alguma PCA em suas aulas, quer seja o slackline (três professores já inseriram), trekking e canoagem no entorno escolar (saída a campo com os alunos, porém feito uma única vez e por um único professor), e o skate (utilizado por dois professores).

A fala de dois participantes demonstra esta questão: 
P18: Eu acho que dá tranquilamente para trabalhar estas práticas de aventura na escola [...] a gente pode mostrar vídeos e fotos, simular e adaptar algumas modalidades na quadra e no pátio e depois discutir com os alunos sobre tudo 0 que foi vivenciado por eles [...].

P9: [...] sem dúvida é bem possível, temos apenas que ter vontade e saber adaptar algumas modalidades para o contexto escolar [...] não dá para eu levar meus alunos em Itacaré ou mesmo pros arredores de llhéus, mas dá pra simular e dar aulas dentro da escola com determinadas práticas como o skate, slackline, e outras mais simples [...].

Sobre tais depoimentos e a respeito dessa possível adaptação em algumas práticas, a Base Nacional (BRASIL, 2017) menciona que se deve levar em consideração as possibilidades ambientais e materiais do contexto. É importante deixar claro que não se trata de reproduzir as condições para a realização da prática, no transcorrer das aulas, tais como elas ocorrem fora da escola. A Base Nacional evidencia que práticas como a corrida de orientação ou o skate, entre tantas outras, não só podem como devem ser transformadas, didática e pedagogicamente, para que sejam tematizadas nas aulas de Educação Física.

No que se refere às experiências que as PCA podem acarretar, mesmo que elas sejam adaptadas às características, estruturas e possibilidades de cada unidade escolar, acreditase que essas práticas podem proporcionar experiências únicas, estimulando novas emoções e sensações nos alunos, por meio de desafios e superação de seus limites pessoais nas vivências de aventura propostas.

Torna-se relevante o papel dos professores de Educação Física, para que essas práticas, ao serem tratadas como conteúdos em aulas, possam ser instrumentos de formação de cidadãos mais engajados e responsáveis, aprendendo a valorizar e respeitar o patrimônio público urbano, adotar uma consciência de preservação ambiental, entre outros exemplos que podem ser trabalhados e/ou abordados pelos professores junto aos alunos.

Por meio de ações didáticas ao inserir e adaptar os esportes de roda nas aulas, como skate, patins e bike, Bocchini e Maldonado (2014) salientam que foi possível refletir, reconhecer e valorizar estes esportes como um patrimônio a ser debatido e problematizado pela Educação Física Escolar, por figurarem-se como parte integrante da Cultura Corporal de Movimento.

Alguns estudos, como os de Dejager (2006), Pereira e Armbrust (2010), Franco et al. (2011), Fernández-Rio e Suarez (2014), Tahara e Darido (2016), entre outros, também comentam e refletem a respeito da necessidade de se realizar adaptações em determinadas PCA, no propósito de que haja o desenvolvimento no contexto das aulas de Educação Física Escolar.

Para ilustrar tais adaptações que se fazem necessárias, Dejager (2006) enfatiza que a escola onde leciona não está localizada em meio natural, não dispõe de materiais específicos, como caiaques, bicicletas e/ou cordas de escalada, além de ter uma quantidade considerável de alunos para as aulas.

Desta forma, a corrida de aventura idealizada por ele teve de ocorrer nas dependências da própria escola, excluindo-se as vivências que necessitavam destes materiais específicos e adicionando-se outros obstáculos que as equipes tiveram que completar durante a prova. Em suma, fez-se uso das ideias centrais das corridas de aventura, porém com muitas adaptações, novas provas e tarefas diversificadas, sem o risco iminente ou uso de equipamentos sofisticados, mostrando-se viável a inserção desta modalidade de aventura em âmbito escolar (DEJAGER, 2006). 
Entende-se que muitas modalidades necessitam de inúmeros materiais específicos para a referida prática, o que pode dificultar sua execução durante as aulas de Educação Física Escolar. Em alguns casos, o próprio professor pode ter algum tipo de material (ou emprestar de conhecidos), por já possuir relativa experiência na modalidade, e desta maneira consegue adaptar uma situação que possibilite aos alunos experimentar diferentes PCA.

Mas, claro, uma série de fatores pode influenciar qual conteúdo vai ser tratado junto aos alunos, vai depender de como o professor vai querer fazer tal abordagem, o nível de conhecimento do docente acerca das diferentes modalidades que compõem as PCA, as condições físicas e materiais da escola, o contexto em que a instituição está localizada, entre outros aspectos que tendem a interferir no processo de inserção de tais práticas em aulas escolares.

\subsection{Dificuldades para a implementação das PCA na escola}

Em relação à categoria das dificuldades e obstáculos que permeiam a implementação das PCA na escola, percebe-se que ainda são muitos os entraves que estão envolvidos neste processo.

A maioria dos professores cita a dificuldade em desenvolver esse conteúdo, seja pela carência de recursos, formação inicial deficitária, vontade dos alunos, risco e perigo nas práticas, entre outros, e, por tais motivos, nunca promoveram a vivência entre os alunos. Como dito anteriormente, apenas quatro professores já ministraram tal conteúdo junto aos alunos.

Em relação aos riscos e perigos atrelados às práticas de aventura, embora não seja foco principal deste estudo abordar essas questões de maneira mais aprofunda, cabe destacar que esses aspectos possuem considerável relevância e merecem atenção especial de professores e demais praticantes. Afinal, a presença de riscos é algo característico e inerente a essas práticas, tornando-se necessário que os professores levem em consideração sua adequada gestão.

A gestão dos riscos para as práticas corporais de aventura na escola deve buscar atender alguns aspectos, como nos alertam Dickson e Gray (2012). Priorizar a comunicação durante todo o planejamento e execução das vivências propostas; promover o envolvimento constante de professores, monitores, alunos e demais envolvidos; a atividade ser monitorada, revista e adequada durante todo o tempo, de acordo com cada contexto onde se desenvolve a prática; verificar e certificar-se dos equipamentos empregados e/ou adaptados para uso, etc., são condutas que devem ser tomadas para que haja a segurança dos alunos e minimização dos riscos durante as atividades.

Torna-se perceptível que, em muitos casos, os professores tendem a abordar apenas aqueles conteúdos sobre os quais têm maior domínio e com os quais se sentem mais à vontade, o que torna, muitas vezes, as aulas de Educação Física geralmente restritas e vinculadas aos esportes coletivos tradicionais. Tal fato acaba por deixar de lado outros componentes relevantes da Cultura Corporal de Movimento, os quais são igualmente importantes em serem contextualizados nas aulas.

Alguns estudos, como os de Franco et al. (2011), Armbrust e Silva (2012), Tahara e Carnicelli Filho (2013), tecem comentários acerca da importância dos professores de Educação 
Física em conhecer as PCA e, quando necessário, sempre se capacitar para desenvolver e tratar adequadamente este conteúdo junto aos alunos em suas aulas na escola.

Em relação às dificuldades para inserção das PCA nas aulas, Franco et al. (2011) mencionam que há muitos obstáculos para desenvolver este conteúdo na Educação Física Escolar, entre os quais estão um maior empenho do professor em buscar estar sempre atualizado e em formação continuada, assim como as condições e estruturas deficitárias da maioria das escolas brasileiras, os recursos materiais insuficientes para uso nas aulas, entre outros aspectos que dificultam este processo.

Dois participantes comentam sobre isso:

P15: [...] entendo que estas práticas necessitam de locais e equipamentos específicos, e no meu caso, na minha escola mal se tem uma bola em boas condições, isso sem falar no estado que a quadra se encontra [...] além do meu pouco conhecimento neste assunto de aventura [...].

P4: [...] são muitas dificuldades que eu enfrento todo dia na minha escola, os alunos só querem saber de jogar o futebol, e pra ser sincero eu nem tenho outro lugar pra fazer algo diferente, essas práticas de aventura [...] e nem posso dizer que conheço bem esse conteúdo pra trabalhar bem em aula [...].

Nesse mesmo sentido, Tomio et al. (2016) realizaram uma pesquisa com professores de Educação Física da educação básica, e, no que diz respeito à inserção dos Esportes Radicais, constatou-se que tais manifestações infelizmente não vêm sendo utilizadas como conteúdo educacional, devido às estruturas e condições ruins da maioria das escolas, além da necessidade de um maior conhecimento sobre a temática, uma vez que alguns professores não sabem como abordá-la devidamente em suas aulas, bem como se desconhece as possibilidades e os benefícios que as PCA podem acarretar ao contexto escolar.

Espera-se que, mesmo ocorrendo inúmeros empecilhos que permeiam (e possivelmente irão permear) este caminho, torna-se necessário que as PCA tenham maiores oportunidades e condições para serem inseridas no contexto da Educação Física Escolar, uma vez que a abordagem desse componente curricular pode propiciar ao aluno a reflexão, o conhecimento e a vivência acerca desse conteúdo (a ser devidamente tratado e contextualizado) em aulas escolares.

\section{CONSIDERAÇÕES FINAIS}

Tomando por base os resultados encontrados nesta pesquisa, percebeu-se que 0 conteúdo referente às PCA (infelizmente) ainda é pouco tratado nas escolas públicas da cidade de llhéus. Torna-se necessário que haja um maior conhecimento por parte dos professores no sentido de conseguirem visualizar situações que permitam aos alunos conhecer e vivenciar determinadas práticas que podem (e deveriam) ser exploradas e adaptadas ao contexto das aulas de Educação Física Escolar.

Vivenciar práticas não tão habituais em aulas, envolver em situações de risco controlado, manusear equipamentos ou materiais diferentes e pouco conhecidos pelos alunos, chance de vivenciar outras manifestações presentes na Cultura Corporal de Movimento, e assim, aumentar seus conhecimentos, experiências e possibilidades de escolhas, entre outros, são alguns dos motivos pelos quais se acredita na necessidade de inclusão destas práticas na escola. Afinal de contas, vale a pena o professor inovar e diversificar as suas aulas? 
Espera-se que as PCA, em nível nacional mediante a Base Nacional (BRASIL, 2017), possam ser cada vez mais um conteúdo a ser ministrado nas aulas de Educação Física Escolar, haja vista que tais práticas estão cada vez mais inseridas e disseminadas no contexto da sociedade atual, e aos poucos têm sido incorporadas no contexto escolar, com novas possibilidades de exploração corporal pelos alunos ao vivenciarem práticas desafiadoras e diferentes daquelas já experimentadas em aulas, como, por exemplo, as modalidades de esportes coletivos.

Não se pode perder de vista que cabe ao professor de Educação Física a tarefa de (tentar) inserir as PCA na medida do possível, respeitando-se os seus conhecimentos sobre tais práticas, as especificidades dos seus locais de docência, as adaptações que se fazem necessárias e a existência de fatores adversos.

Sobre tais fatores adversos, entre eles a chance dos alunos terem possíveis acidentes durante as práticas propostas na escola, sugere-se a importância e a necessidade de pesquisadores, professores e demais envolvidos ampliar as discussões sobre a exposição e a gestão de riscos em novas investigações acadêmico-científicas, alargando contribuições e gerando novos elementos para futuras discussões em relação a essa área de estudo no Brasil.

Torna-se premente que exista um favorecimento e contribuições cada vez maiores para que haja a formação de um (aluno) cidadão crítico e consciente acerca das práticas corporais que se configuram no contexto da Cultura Corporal de Movimento. E diante de tal fato é que se imagina que as PCA merecem (e devem) ser discutidas no âmbito das aulas de Educação Física Escolar, por apresentarem considerável potencial pedagógico para serem tratadas e contextualizadas junto aos alunos.

\section{REFERÊNCIAS}

ARMBRUST, Igor; SILVA, Sheila Aparecida Pereira dos Santos. Pluralidade Cultural: os esportes radicais na Educação Física Escolar. Movimento, v.18, n.1, p.281-300, 2012.

BARDIN, Laurence. Análise de Conteúdo. 3. ed. Lisboa: Edições70, 2004.

BETRÁN, Javier Oliveira; BETRÁN, Alberto Oliveira. Proposta Pedagógica para as Atividades Físicas de Aventura na Natureza (AFAN) na Educação Física do Ensino Médio. In: MARINHO, Alcyane; BRUHNS, Heloísa Turini (Org.). Viagens, Lazer e Esporte: o espaço da natureza. Barueri: Manole, 2006. p.180-209.

BOCCHINI, Daniel; MALDONADO, Daniel Teixeira. Andando sobre rodas nas aulas de Educação Física escolar. Motrivivência, v.26, n.43, p.277-286, dez. 2014.

BRACHT, Valter. Sociologia Crítica do Esporte: uma introdução. 3. ed. ljuí: Unijuí, 2005.

BRASIL. Ministério da Educação. Base Nacional Comum Curricular. Brasília: MEC, 2017.

CAPAVERDE, Mariane Rech; MEDEIROS, Tiago Nunes; ALVES, Sérgio Luiz Chaves. Esporte de Aventura nas aulas de Educação Física: uma alternativa ao alcance dos profissionais? Vento e

Movimento, v. 1, n. 1, p. 49-59, 2012. 
DEJAGER, Dan. Adventure Racing CORE: A Nontraditional Approach to the Physical Education Lesson. Journal of Physical Education, Recreation \& Dance, v.77, n.6, p.25-33, 2006.

DICKSON, Tracey J.; GRAY, Tonia L. Risk Management in the Outdoors: a whole of organization approach for education, sport e recreation. Melbourne: Cambridge University, 2012.

FERNÁNDEZ-RÍO, Javier; SUAREZ, Carlos. Feasibility and students' preliminary views on parkour in a group of primary school children. Physical Education and Sport Pedagogy, v. 21, n. 3, p.1-14, 2014.

FRANCO, Laércio Claro Pereira et al. Atividades Físicas de Aventura: Proposta de um Conteúdo na Educação Física Escolar no Ensino Fundamental. Arquivos em Movimento, v.7, n.2, p.18-35, jul/dez. 2011.

FRANCO, Laércio Claro Pereira; CAVASINI, Rodrigo; DARIDO, Suraya Cristina. Práticas corporais de aventura. In: GONZÁLEZ, Fernando Jaime; DARIDO, Suraya Cristina; OLIVEIRA, Amauri Aparecido Bássoli de (Orgs.). Lutas, Capoeira e Práticas corporais de aventura: práticas corporais e a organização do conhecimento. Maringá: Eduem, 2014. p.101-135.

FREITAS, Tamires Alvarado et al. Avaliação da implementação de um programa de práticas corporais de aventura na Educação Física escolar. Arquivos em Movimento, v.12, n.1, p.4-16, jan./jun. 2016.

FRIZZO, Giovanni. Os jogos escolares como mecanismos de manutenção e eliminação: uma crítica à lógica esportiva na escola. Movimento, v.19, n.4, p.163-180, 2013.

INÁCIO, Humberto Luís de Deus et al. Práticas corporais de aventura na escola: possibilidades e desafios - reflexões para além da Base Nacional Comum Curricular. Motrivivência, v.28, n.48, p.168187, 2016.

KUNZ, Elenor. Transformação didático-pedagógica do esporte. 6. ed. ljuí: Unijuí, 2004.

MALDONADO, Daniel Teixeira; SILVA, Sheila Aparecida Pereira dos Santos. Deportes extremos en la escuela: las tres dimensiones de los contenidos y el desarrollo del pensamiento crítico. Innovación Educativa, n.25, p.249-267, 2015.

MARCONI, Marina de Andrade; LAKATOS, Eva Maria. Técnicas de pesquisa: planejamento e execução de pesquisas; amostragens e técnicas de pesquisa; elaboração, análise e interpretação de dados. 5. ed. São Paulo: Atlas, 2002.

PEREIRA, Dimitri Wuo; ARMBRUST Igor. Pedagogia da Aventura: os esportes radicais, de aventura e de ação na escola. Jundiaí: Fontoura; 2010.

RICHARDSON, Roberto Jarry. Pesquisa social: métodos e técnicas. 3. ed. São Paulo: Atlas, 1999.

RODRIGUES, Heitor de Andrade; DARIDO, Suraya Cristina. A técnica esportiva em aulas de Educação Física: um olhar sobre as tendências sócio-culturais. Movimento, v.14, n.2, p.139-154, 2008.

SCHWARTZ, Gisele Maria. Atividades de aventura: criatividade, valores, interfaces e possibilidades de vivências. In: FIGUEIREDO, Juliana de Paula et al. (Orgs.). Atividades de Aventura: vivências para diferentes faixas etárias. São Paulo: Supimpa, 2018. p.10-21.

SEVERINO, Antonio Joaquim; PEREIRA, D. W.; SANTOS, V. S. F. dos. Aventura e Educação na Base Nacional Comum. EccoS - Revista Cientffica, n.41, p.107-125, set./dez. 2016. 
SOARES, Carmen Lúcia et al. (Org.). Metodologia do ensino de Educação Física. São Paulo: Cortez, 1992.

SUTHERLAND, Sue; LEGGE, Maurren. The Possibilities of "Doing" Outdoor and/or Adventure Education in Physical Education/Teacher Education. Journal of Teaching in Physical Education, v.35, n.4, p.299-312, 2016.

TAHARA, Alexander Klein; CARNICELLI FILHO, Sandro. A presença das atividades de aventura nas aulas de Educação Física. Arquivos de Ciências do Esporte, v.1, n.1, p.60-66, 2013.

TAHARA, Alexander Klein; DARIDO, Suraya Cristina. Práticas corporais de aventura em aulas de Educação Física na escola. Conexões, v.14, n.2, p.113-136, 2016.

THOMAS, Jerry R.; NELSON, Jack K.; SILVERMAN, Stephen J. Métodos de pesquisa em atividade física. 5. ed. Porto Alegre: Artmed, 2007.

TOMIO, Bruno Wilwert et al. Os esportes radicais como conteúdo interdisciplinar no contexto escolar. Conexões, v. 14, n. 1, p. 104-129, jan./mar. 2016. 
